\title{
Relações de Estrutura Atividade e Análise Multivariada para Inibidores da Acetilcolinesterase.
}

*Mônica Abreu Silva ${ }^{1}$ (PQ), Alessandra Sofia Kiametis ${ }^{1}$ (PQ), Luiz A. S. Romeiro ${ }^{1}(P Q)$, Ricardo Gargano ${ }^{1}$ (PQ).

abreumnc@gmail.com

\author{
${ }^{1}$ Universidade de Brasília. CP04455, Brasília, DF, CEP 70919-970, Brasil.
}

\section{Introdução}

A Doença de Alzheimer (DA) é um mal neurodegenerativo progressivo, que compromete o sistema cognitivo causando demência. Estatisticamente é uma das demencias que mais afeta idosos com idade superior a 65 anos. Bioquimicamente, resulta da redução nos níveis de acetilcolina (ACh) no processo sináptico cuja restauração pode ser feita por meio da inibição reversível da enzima acetilcolinesterase (AChE), recuperando a concentração central da ACh. Neste contexto, realizamos um estudo teório baseado em Quantitative structure-activity relationship (QSAR) relacionando propriedades estruturais e eletrônicas e atividade biológica de compostos lipídeos fenólicos não-isoprenóides do líquido da castanha de caju (Anacardium occidentale), candidatos a inibidores da enzima acetilcolinesterase (AChEI). Além disso foi realizado o estudo de interação ligante-proteína por meio do Docking Molecular para analizar os modos de interaçãoes desses candidatos com a AChE, por fim os resultados QSAR e Docking foram equiparados gerando o mapa preditivo desses descritores.

\section{Resultados e Discussão}

O estudo teórico foi realizado a partir de cálculos de otimização de geometrias dos candidatos AChEI à nível ab initio. Os cálculos foram realizados com nível de cálculo B3LYP, conjunto de bases 6-311+G(2d,p) via pacote computacional Gausian09. Através da correlação entre os descritores eletrônicos dos candidatos com alto percentual de inibição e os demais candidatos com diferentes grupos substituintes, construímos uma análise baseada nas componentes principais (PCA) gerando clusters entre moléculas com atividades parecidas, apontando os descritores mais relevantes para o planejamento de fármacos com atividade melhorada. Também realizamos a análise de correlação entre os descritores, através do coeficiente de correlação de Pearson, determinando quais dos descritores apontados pela PCA teriam mais peso na correspondencia estrutura-atividade.

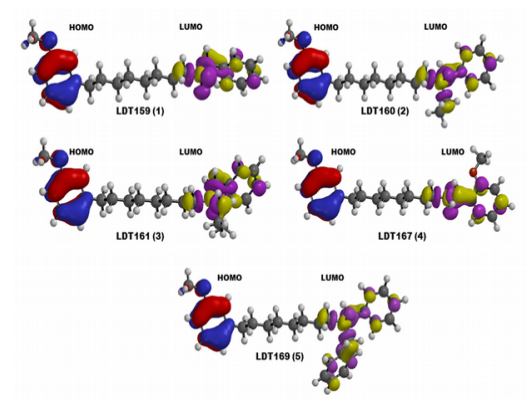

Fig1: Superfície de densidade eletrônica dos orbitais HOMO e LUMO, para os deriva-dos benzilamínicos do cardanol.

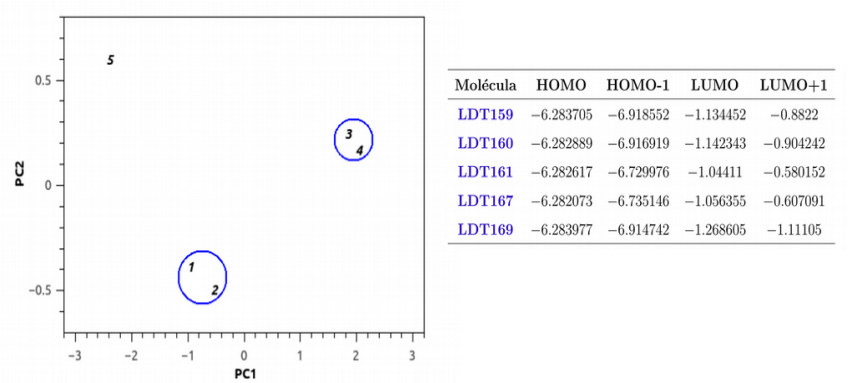

Fig2: Disposição dos candidatos nas duas componentes principais e valores das propriedades HOMO-1(eV), HOMO(eV), LUMO(eV) e LUMO+1(eV) utilizadas na PCA (derivados benzilamínicos). 


\section{Conclusões}

Descritores eletrônicos como energias do HOMO-1, HOMO, LUMO, LUMO+1 demostraram-se importantes ao agrupar potentes AChEI. O PCA foi capaz de agrupar com eficiencia ligantes com atividades biológicas comparáveis. O coeficiente de Pearson reescalonou os descritores com maior relevância. Os resultados de Docking, orientação preferencial dos candidatos, elucidou os possíveis tipos de interações dos candidatos com a proteína e avaliou essas interações segundo as atividades biológicas de cada candidato.

\section{Agradecimentos:}

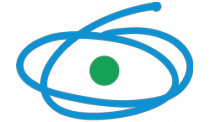

CAPES

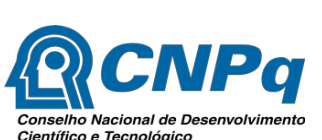

Conselho Nacional de Des
Cientifico e Tecnológico
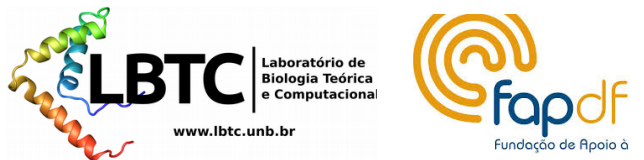

\section{Referências}

1. DVIR, H. et al. Acetylcholinesterase: from 3d structure to function. Chemico-biological interactions, Elsevier, v. 187, n. 1, p. 10-22, 2010.

2. BURKE, K. Perspective on density functional theory. The Journal of chemical physics, AIP Publishing, v. 136, n. 15, p. 150901, 2012.

3. LEMES, L. F. N. et al. Cardanol-derived ache inhibitors: Towards the development of dual binding derivatives for alzheimer’s disease. European journal of medicinal chemistry, Elsevier, v. 108, p. 687-700, 2016.

4. VALASANI, K. R. et al. Structure based design, synthesis, pharmacophore modeling, virtual screening, and molecular docking studies for identification of novel cyclophilin d inhibitors. Journal of chemical information and modeling, ACS Publications, v. 54, n. 3, p.902-912, 2014. 